\title{
Help-Seeking Behavior and Treatment Barriers in Anxiety Disorders: Results from a Representative German Community Survey
}

\author{
Ingmar Heinig ${ }^{1}(\mathbb{D}) \cdot$ Hans-Ulrich Wittchen ${ }^{1,2}$ (D) $\cdot$ Susanne Knappe ${ }^{1}$ (D)
}

Received: 14 July 2020 / Accepted: 23 December 2020 / Published online: 20 January 2021

(c) The Author(s) 2021

\begin{abstract}
Although effective therapies exist, treatment rates of anxiety disorders (AD) are low, raising the question why affected individuals do not receive treatment. We provide data from the nationally representative German Health Interview and Examination Survey-2011 (DEGS1) on the help-seeking behavior and perceived treatment barriers of 650 subjects with Diagnostic and Statistical Manual of Mental Disorders' (DSM-IV AD). Only $26 \%$ of all cases with AD in the community reported having had contact with mental health services because of their anxiety problems in their lifetime. $16 \%$ were currently receiving professional help, most frequently by psychotherapists $(8 \%)$, psychiatrists $(5 \%)$ and general practitioners (5\%). $40 \%$ of all cases never even considered seeking help and $31 \%$ reported barriers to treatment, such as self-reliance $(18 \%)$ or beliefs that treatments were ineffective (9\%), unavailable (8\%) or too stigmatizing (7\%). Measures to increase treatment rates should thus target individual as well as public attitudes and health literacy to increase awareness of and access to evidence-based interventions.
\end{abstract}

Keywords Anxiety disorders $\cdot$ Service use $\cdot$ Help seeking $\cdot$ Treatment barriers $\cdot$ Dropout

\section{Introduction}

Anxiety disorders (AD) are the most prevalent group of mental disorders and are responsible for high levels of individual and societal disease burden (Alonso et al. 2004a; Jacobi et al. 2014; Kessler et al. 2012; Wittchen and Jacobi 2005; Wittchen et al. 2011). For example, individuals with AD report 5.9 days with functional impairment per month (Mack et al. 2015) and societal costs are estimated at more than $1.000 €$ per case and year in Europe (Gustavsson et al. 2011). AD are successfully treatable with evidence-based psychological and pharmacological interventions, such as

Supplementary information The online version of this article (https://doi.org/10.1007/s10597-020-00767-5) contains supplementary material, which is available to authorized users.

Ingmar Heinig

ingmar.heinig@tu-dresden.de

1 Institute of Clinical Psychology and Psychotherapy, Technische Universität Dresden, Chemnitzer Str. 46, 01187 Dresden, Germany

2 Department of Psychiatry and Psychotherapy, Ludwig-Maximilians-Universität München, Nußbaumstr. 7, 80336 Munich, Germany cognitive-behavioral treatments (Bandelow et al. 2014; Butler et al. 2006; Carpenter et al. 2018; Norton and Price 2007). However, as demonstrated by numerous studies since the 1980s, the majority of affected individuals do not receive professional help (Essau 2005; Jacobi et al. 2004; Kessler et al. 1994; Magee et al. 1996; Runge et al. 2008; Wang et al. 2007; Wittchen et al. 1999). It is reported that only around half of all cases have ever contacted mental health services, and about one quarter have seen a specialized professional (Alonso et al. 2004b; Bijl and Ravelli 2000; Wittchen et al. 2011). Even worse, there is an average delay of six years between onset and first service use (Mack et al. 2014). Service use in $\mathrm{AD}$ has apparently not been increasing significantly during the last three decades (De Graaf et al. 2012; Wang et al. 2005). This may indicate that relevant treatment barriers have not been sufficiently targeted throughout this time (Mack et al. 2014). The present study will thus examine characteristics of help-seeking across different AD, as well as putative reasons not to seek treatment.

Service use, help-seeking, disorder-specific treatment and treatment completion can all be seen as sequential steps of health care utilization (note that while help-seeking can also occur at an informal level, i.e. support from friends, spiritual care etc., in this study we exclusively refer to formal 
help-seeking). Service use refers to any contact with mental health-care providers, irrespective of its purpose (Alonso et al. 2004b; Wang et al. 2007; Wittchen and Jacobi 2001). Disorder-specific help-seeking denotes that an individual addresses their anxiety symptoms if in contact with a mental health-care provider (Mackenzie et al. 2012). Further, a disorder-specific treatment is present if the concerned individual has repeated contacts with a specialized professional and disorder-specific interventions are applied (Fernández et al. 2007; Wang et al. 2007).

To date, extensive data on general service use in $\mathrm{AD}$ is available (Alonso et al. 2004b; Mack et al. 2014; Wang et al. 2005). However, service use rates do not fully reflect care and treatment of AD: A substantial fraction of individuals with $\mathrm{AD}$ are in contact with help services but present with other problems such as somatic or depressive symptoms (Asp et al. 2020; Kirmayer et al. 1993; Zimmerman and Chelminski 2003). It is reported that less than half of the potential generalized and social anxiety diagnoses are detected in primary and outpatient psychosomatic services (Wiltink et al. 2010; Wittchen et al. 2002). Consequently, only $30 \%-70 \%$ of service users with $\mathrm{AD}$ receive an anxiety-specific treatment (Fernández et al. 2007; Roberge et al. 2011; Stein et al. 2004). Moreover, help-seeking rates seem to differ between the various types of AD. For example, individuals with panic or generalized anxiety disorder (GAD) are reportedly high utilizers of treatment services (Wittchen et al. 2003), whereas individuals with specific phobias (SPEC) rarely seek any treatment (Mackenzie et al. 2012). Treatment barriers might also differ between AD (Olfson et al. 2000), but disorder-specific barrier profiles have rarely been reported. The present study thus focusses on disorderspecific help-seeking and its barriers.

Help-seeking for mental health problems is associated with sociodemographic factors such as age, gender, and urbanization, with need factors such as disorder severity, comorbidity, or impairment, and with enabling factors such as knowledge on mental health services (Goodwin and Andersen 2002). Barriers to help-seeking may be deliberately perceived, i.e. an individual faces specific obstacles when trying to seek help, or unperceived, i.e. an individual does not even consider seeking help and therefore does not experience any barrier. Typical perceived barriers in individuals with $\mathrm{AD}$ are knowledge deficits (e.g. knowing where he/she can seek help), fear of stigma and reliance on selfmanagement strategies (Clark et al. 2018; Coles and Coleman 2010; Mojtabai et al. 2011).

Even when individuals with $\mathrm{AD}$ enroll in treatment, they do not necessarily receive adequate therapy in terms of type or dosage, nor do they always complete a treatment. They may drop out of therapy (Fernandez et al. 2015; Taylor et al. 2012) prematurely, depending for example on attitudes and expectations towards treatment (Bélanger et al.
2017; Santana and Fontenelle 2011). Treatment dropout is typically associated with increased economic costs of the illness (Konnopka et al. 2009; Wittchen et al. 2011). The assessment of reasons for dropout is therefore an important supplement to overcome treatment barriers.

In sum, although low service use has been described for $\mathrm{AD}$, evidence on disorder-specific help-seeking behavior and on correlates and predictors of service utilization is sparse. We therefore aim to report (1) disorder-specific help-seeking rates for different health sectors and providers, (2) information on the extent and type of treatment with the most frequently utilized specialized services, (3) predictors of help-seeking, and (4) information on treatment barriers and dropout reasons in AD.

\section{Methods}

\section{Sampling}

Data for this study stem from the German Health Interview and Examination Survey for Adults-Mental Health module (DEGS-MH, 2011), a nationally representative survey designed to examine prevalence, impairment, and helpseeking for mental disorders in the German adult population (Jacobi et al. 2013, 2014). DEGS-MH is a module of the German Health Interview and Examination survey (DEGS1, Scheidt-Nave et al. 2012). DEGS1 used a two-stage stratified cluster sample $(\mathrm{N}=8152)$, based on (1) 180 sample points across Germany, stratified for grade of urbanization, population density and administrative borders (2) random selection of participants from local population registries at each sample point (Kamtsiuris et al. 2013). Participants of the previous German health survey, dating from 1998, were also included. DEGS1 participants were eligible for DEGSMH if they fell into the specified age range (18-79 years), had fully completed DEGS1, had given informed consent for DEGS-MH and were available for the survey. Of 6028 eligible individuals, 4483 (74.4\%) completed DEGS-MH. $8.5 \%$ were excluded because they refused to participate, $3.3 \%$ could not be contacted, and $13.8 \%$ took part in a reduced core survey. Assessments were conducted by clinically trained assessors at all 180 sample points by way of computer-assisted personal interviews between 09/2009 and 03/2012 (for details see Jacobi et al. 2013). The present study used the subsample of 650 cases who met criteria for a 12-month AD according to DSM-IV-TR. Sample characteristics are displayed in Table 1. 
Table 1 Sample characteristics

\begin{tabular}{|c|c|c|c|c|c|c|c|c|c|c|c|c|c|}
\hline \multirow{3}{*}{ Demographics } & \multirow[t]{2}{*}{$\mathrm{N}$} & \multicolumn{2}{|c|}{ Any AD } & \multicolumn{2}{|l|}{ PD } & \multicolumn{2}{|l|}{ AG } & \multicolumn{2}{|l|}{ SAD } & \multicolumn{2}{|l|}{ GAD } & \multicolumn{2}{|c|}{ SPEC } \\
\hline & & \multicolumn{2}{|l|}{650} & \multicolumn{2}{|l|}{93} & \multicolumn{2}{|l|}{164} & \multicolumn{2}{|l|}{95} & \multicolumn{2}{|l|}{87} & \multicolumn{2}{|l|}{423} \\
\hline & & & & & & & & & & & & & \\
\hline Age & $\mathrm{M}(\mathrm{SD})$ & 45.2 & $(15.7)$ & 45.7 & $(12.0)$ & 46.5 & (15.7) & 39.6 & $(12.9)$ & 43.8 & $(15.1)$ & 46.1 & $(16.3)$ \\
\hline Female sex & $\%(\mathrm{~N})$ & 70.4 & $(458)$ & 71.3 & (70) & 71.5 & (113) & 67.6 & (57) & 66.5 & $(55)$ & 75.5 & $(317)$ \\
\hline Employed & $\%(\mathrm{~N})$ & 56.8 & $(362)$ & 57.9 & $(55)$ & 50.9 & (83) & 44.5 & (48) & 51.4 & (44) & 54.9 & $(232)$ \\
\hline Living with a partner & $\%(\mathrm{~N})$ & 70.4 & $(460)$ & 66.6 & $(58)$ & 64.3 & $(103)$ & 64.3 & (64) & 67.3 & (64) & 71.8 & $(302)$ \\
\hline \multicolumn{14}{|l|}{ Clinical characteristics } \\
\hline Age of onset & $\mathrm{M}(\mathrm{SD})$ & 36.7 & $(18.6)$ & 31.1 & $(14.8)$ & 30.3 & $(17.3)$ & 20.2 & $(13.2)$ & 32.9 & $(15.7)$ & 40.4 & $(18.9)$ \\
\hline Duration (years) & $\mathrm{M}(\mathrm{SD})$ & 8.5 & $(13.6)$ & 14.6 & $(13.3)$ & 16.2 & $(15.5)$ & 19.4 & $(16.0)$ & 10.9 & $(14.0)$ & 5.7 & $(12.4)$ \\
\hline Disability (y/n) & $\%(\mathrm{~N})$ & 40.0 & (232) & 64.8 & $(58)$ & 49.1 & (83) & 71.3 & (66) & 60.6 & (46) & 34.2 & $(127)$ \\
\hline No. of comorbidities & $\mathrm{M}(\mathrm{SD})$ & 1.4 & (1.6) & 2.0 & $(2.0)$ & 1.9 & (2.0) & 2.7 & (2.4) & 1.9 & (1.9) & 1.4 & $(1.7)$ \\
\hline Comorbid AD (y/n) & $\%(\mathrm{~N})$ & 27.0 & $(155)$ & 67.1 & $(59)$ & 65.5 & $(102)$ & 59.8 & (58) & 44.7 & (34) & 32.2 & (114) \\
\hline Comorbid DD(y/n) & $\%(\mathrm{~N})$ & 27.7 & (169) & 32.7 & (33) & 33.8 & $(56)$ & 43.4 & (39) & 54.3 & (46) & 24.3 & (86) \\
\hline
\end{tabular}

$\mathrm{AD}=$ anxiety disorder, $\mathrm{PD}=$ panic disorder, $\mathrm{AG}=$ agoraphobia, $\mathrm{SAD}=$ social anxiety disorder, $\mathrm{GAD}=$ generalized anxiety disorder, $\mathrm{SPEC}=\mathrm{spe}-$ cific phobia, $\mathrm{DD}=$ depressive disorder

\section{Measures}

\section{Anxiety Disorders}

AD included in this study were panic disorder (PD), agoraphobia (AG), social anxiety disorder (SAD), GAD and SPEC. Diagnoses were assessed using the DIA-X software, a computerized German version of the Composite International Diagnostic Interview (CIDI; Wittchen and Pfister 1997). The CIDI is a fully standardized interview with good reliability and validity for AD (Reed et al. 1998; Wittchen 1994; Wittchen et al. 1998). Diagnoses were assessed according to the Diagnostic and Statistical Manual of Mental Disorders' (DSM-IV-TR) criteria during the past 12 months.

\section{Service Use}

Service use was estimated as a condition for help-seeking (see below). The CIDI included a section on service use behaviors and disability, placed at the end of the interview. Participants were first asked whether they had ever thought about or had been recommended professional help due to mental health or psychosomatic problems. They were then presented a list with 27 services to indicate which of them they had ever contacted because of mental health problems. The list of services included primary care (i.e., general practitioners), inpatient (e.g., psychiatric or psychosomatic hospitals) and outpatient institutions (e.g., psychiatrists, outpatient clinics), as well as complementary institutions (e.g., counselling centers, helplines; full list available upon request). For each institution, in-depth questions were asked to explore occasion, duration and type of intervention. This information was used to calculate 12-month vs. lifetime help-seeking rates.

\section{Disorder-Specific Help-Seeking}

Participants were considered as help-seekers if they had (1) used at least one health service from the list of health care services and (2) had at least once talked to a professional about their anxiety symptoms. The latter information was included in the CIDI's diagnostic section for each AD ("Have you ever talked to a professional, e.g. medical doctor, psychologist, social worker, counsellor, clergy, about these problems?"). For SPEC, the question: "For what reason did you visit or contact these institutions?", asked in the CIDI's service use section, was used to indicate disorderspecific help-seeking.

\section{Disability}

Current disability due to mental disorders was assessed as a potential predictor of help-seeking at the very end of the interview by asking participants whether they had been "at least partly impaired in their everyday activities (work, household, etc.) due to mental or psychological problems" at any day within the past four weeks.

\section{Treatment Barriers and Reasons for Dropout}

The CIDI's service use section also included gated questions regarding treatment barriers and potential reasons for dropout. Those who agreed to have ever thought about seeking professional help (see above) were then asked for treatment 
barriers using a list of 13 possible barriers (yes/no): "Has it ever happened that you thought about or have been recommended professional help, but then did not do it? Why was that?" Participants who never thought about seeking help were not asked for barriers and are here reported as individuals with "unperceived barriers". Participants who reported to have discontinued at least one treatment were asked for dropout reasons using a list of 16 possible dropout reasons (yes/no). Item lists for services, barriers and dropout reasons are available in the supplement.

\section{Statistical Analysis}

Statistical analyses were conducted using Stata 14.2 (StataCorp 2017). To ensure representativity for the German population, post stratification weights based on 11 demographic, socio-economic and geographic variables (e.g., age, nationality, region) and the probability to participate in the DEGS-MH module were applied in all analyses and weighted percentages, means, standard deviations and confidence intervals (CIs) are reported. A description of the weighting procedure is given by Jacobi et al. (2013). To test potential predictors of help-seeking, weighted logistic regression was used and odds ratios (OR) are reported. Tests were two-sided with $\alpha=0.05$.

\section{Results}

\section{Prevalence and Type of Disorder-Specific Help-Seeking}

\section{Lifetime Help-Seeking}

Among all cases with a 12-month AD, 26.0\% reported lifetime use of mental health services due to their disorder. Rates ranged from 9.5\% in SPEC to 67.3\% in PD (see Table 2). The most frequently used outpatient services were psychological and medical psychotherapists (16.7\%), psychiatrists (9.2\%), and GPs (8.1\%). $5.1 \%$ contacted other outpatient services, including outpatient clinics (3.1\%), other psychologists $(2.2 \%)$, social-psychiatric services $(0.7 \%)$, and others $(1.1 \%)$. A remarkable $11.2 \%$ reported inpatient service use like psychosomatic hospitals $(6.6 \%)$, psychiatric hospitals (3.8\%), or daycare clinics (3.0\%; other $1.7 \%$ ). $6.4 \%$ reported using what is labeled as "complementary services" (counseling centers, $5.6 \%$, self-help groups, $0.3 \%$, other $1.5 \%$ ) for their AD symptoms. The ranking of most frequently used services was equal across all $\mathrm{AD}$. On average, help-seekers reported to have consulted $2.5(S D=1.7)$ different services in their lifetime. The number of services contacted was highest in $\operatorname{SAD}(3.2, S D=1.8)$ and lowest in $\operatorname{GAD}(1.9, S D=1.7)$.
Table 2 Disorder-specific helpseeking in $\mathrm{AD}$

\begin{tabular}{|c|c|c|c|c|c|c|c|c|c|c|c|c|}
\hline & \multicolumn{2}{|c|}{ Any AD } & \multicolumn{2}{|l|}{ PD } & \multicolumn{2}{|c|}{ AG } & \multicolumn{2}{|c|}{ SAD } & \multicolumn{2}{|c|}{ GAD } & \multicolumn{2}{|c|}{ SPEC } \\
\hline & $\mathrm{N}$ & $\%$ & $\mathrm{~N}$ & $\%$ & $\mathrm{~N}$ & $\%$ & $\mathrm{~N}$ & $\%$ & $\mathrm{~N}$ & $\%$ & $\mathrm{~N}$ & $\%$ \\
\hline Lifetime help-seeking & 155 & 26.0 & 59 & 67.3 & 56 & 36.9 & 51 & 53.3 & 39 & 50.9 & 26 & 9.5 \\
\hline Primary care & 58 & 8.1 & 24 & 28.9 & 24 & 13.2 & 25 & 22.7 & 10 & 9.5 & 13 & 3.9 \\
\hline Outpatient services & 129 & 22.0 & 52 & 61.3 & 49 & 30.2 & 46 & 50.1 & 28 & 39.3 & 24 & 8.2 \\
\hline Psychotherapist & 89 & 16.7 & 37 & 45.5 & 34 & 24.1 & 37 & 43.4 & 18 & 26.7 & 17 & 6.1 \\
\hline Psychiatrist & 63 & 9.2 & 30 & 33.4 & 30 & 18.1 & 24 & 25.6 & 8 & 7.9 & 10 & 3.0 \\
\hline Other & 32 & 5.1 & 9 & 12.3 & 13 & 7.7 & 14 & 12.2 & 7 & 8.5 & 8 & 2.8 \\
\hline Inpatient services & 67 & 11.2 & 32 & 37.0 & 30 & 20.3 & 26 & 24.3 & 14 & 12.0 & 10 & 4.0 \\
\hline Complementary services & 31 & 6.4 & 9 & 14.4 & 14 & 10.1 & 13 & 17.9 & 9 & 14.3 & 5 & 2.2 \\
\hline 12-month help-seeking & 92 & 15.9 & 36 & 41.8 & 34 & 22.6 & 35 & 37.5 & 29 & 40.4 & 12 & 3.9 \\
\hline Primary care & 33 & 4.6 & 15 & 16.6 & 10 & 5.6 & 12 & 9.5 & 8 & 6.5 & 6 & 2.1 \\
\hline Outpatient services & 69 & 12.4 & 29 & 35.3 & 30 & 19.2 & 29 & 32.5 & 17 & 26.7 & 12 & 3.9 \\
\hline Psychotherapist & 38 & 7.9 & 18 & 21.3 & 17 & 14.1 & 17 & 23.3 & 9 & 15.4 & 7 & 2.0 \\
\hline Psychiatrist & 30 & 5.1 & 13 & 18.3 & 15 & 10.9 & 13 & 15.2 & 4 & 4.9 & 5 & 1.9 \\
\hline Other & 12 & 2.4 & 5 & 7.7 & 5 & 3.3 & 5 & 5.0 & 4 & 6.5 & 3 & 1.1 \\
\hline Inpatient services & 13 & 1.8 & 7 & 7.8 & 7 & 3.3 & 6 & 4.1 & 5 & 4.6 & 1 & 0.1 \\
\hline Complementary services & 10 & 3.2 & 3 & 6.8 & 5 & 4.9 & 4 & 7.7 & 3 & 9.8 & 2 & 0.6 \\
\hline
\end{tabular}

$\mathrm{AD}=$ anxiety disorder, $\mathrm{PD}=$ panic disorder, $\mathrm{AG}=$ agoraphobia, $\mathrm{SAD}=$ social anxiety disorder, $\mathrm{GAD}=$ generalized anxiety disorder, $\mathrm{SPEC}=$ specific phobia 


\section{2-Month Help-Seeking}

In the past year, $15.9 \%$ of all cases with 12-month $\mathrm{AD}$ contacted mental health services to manage their disorder, ranging from $3.9 \%$ in SPEC to $41.8 \%$ in PD (see Table 2). The most frequently used services were psychotherapists (7.9\%), psychiatrists (5.1\%) and GPs (4.6\%). 2.4\% contacted other outpatient services (outpatient clinics $1.4 \%$, other psychologists $0.7 \%$, social-psychiatric services $0.3 \%$, others $0.4 \%$ ). $1.8 \%$ used inpatient services (psychosomatic clinics $0.7 \%$, psychiatric hospitals $0.4 \%$, daycare clinics $0.2 \%$, neurological clinics $0.2 \%$, other $0.3 \%$ ), and $3.2 \%$ used complementary services (counseling centers $2.7 \%$, self-help groups $0.1 \%$, other $0.4 \%$ ) for AD symptoms. The ranking of most frequently used services was different in GAD, were counselling centers were contacted relatively more often. $46.8 \%$ of help-seekers had used more than one service in the last 12 months $(M=1.6, S D=0.8)$.

SPEC constituted the largest diagnostic group in the sample and, at the same time, showed the lowest help-seeking rates. Since SPEC are also characterized by lower impairment in daily life and lower perceived need for help compared to other AD (Mack et al. 2015 also see severity indicators in Table 1), they might negatively bias our interpretation of help-seeking rates. We therefore additionally calculated help-seeking rates (Table 2, column 1) without SPEC. This resulted in an overall 12-month help-seeking rate of $20.0 \%$ (primary care $5.7 \%$, outpatient services $15.6 \%$, inpatient services $2.3 \%$, complementary services $4.1 \%$ ).

\section{Factors Associated with Help-Seeking}

In univariate regressions using the complete sample $(\mathrm{N}=650)$, predisposing and enabling factors (age, current partnership, employment and urbanization), as well as all need factors were associated with help-seeking (see Table 3 ). As anxiety comorbidity showed very large CIs, we repeated the analysis using robust estimation with the Huber-White sandwich matrix. Here, urbanization no longer predicted help-seeking ( $O R=0.86, C I=0.48-1.57$ for 100-500 $\mathrm{T}$ inhabitants) and higher education emerged as a predictor ( $O R=0.44, C I=0.20-0.97)$. The $\mathrm{OR}$ for more three or more comorbid AD was $13.22(C I=6.71-26.06)$. In a multivariate regression including all variables, only age $\geq 65$ years $(O R=0.13, C I=0.04-0.44)$ and the need factors "anxiety comorbidity" $(O R=8.78, C I=3.05-25.26$ for three AD compared to only one $\mathrm{AD}$ ) and "presence of disability" $(O R=4.91, C I=2.33-10.35)$ remained as predictors.

\section{Characteristics of Specialized Treatments}

Of those cases with lifetime help-seeking with a psychotherapist or psychiatrist, 92 (79.3\%) answered more detailed questions on treatment characteristics (see Table 4).

Treatment sessions with psychiatrists were typically shorter than 30 min (80.4\% of cases). Psychiatrists predominantly delivered psychopharmacological interventions (76.9\%) or some type of individual psychotherapy (56.2\%). Cognitive behavioral therapy (CBT) was rarely mentioned (2.6\%), despite being a first line treatment. The average timelapse from first treatment contact to the last was 11.3 years $(S D=15.9, M=5.0)$, with an average of 5.6 sessions per year $(S D=5.9, M=4.0$, values calculated for therapies that had been ongoing for at least one year), and a total number of about 30 sessions. On average, treatment by psychiatrists may thus be described as long-lasting treatment with rare contact.

Treatment by psychotherapists was delivered as a shortterm treatment in about $40 \%$ of cases (i.e., up to 30 sessions) and as a long-term treatment in $60 \%$ of cases $(30+$ sessions; note that individuals summed up sessions if they underwent more than one therapy). Duration of psychotherapy sessions was usually $50 \mathrm{~min}$, as prescribed by reimbursement rules in Germany. 29.7\% of participants with psychotherapy reported specifically having received some form of CBT, $70.1 \%$ any other type of psychotherapy. On average, patients reported having been in psychotherapy for 4.2 years $(S D=5.8, M=2.0)$ and received 23.2 sessions per year $(S D=20.8, M=15.3)$.

In both groups (psychiatrists and psychotherapists), about $50 \%$ of patients reported being fully or largely satisfied with their psychotherapeutic or psychiatric therapies. Dissatisfaction with treatment was associated with higher probability of dropout $(O R=1.70, \mathrm{CI}=1.20-2.41)$.

\section{Treatment Barriers}

$31.3 \%(\mathrm{~N}=187)$ of all cases reported barriers to treatment (Table 5). Another 39.9\% ( $=285)$ never considered seeking help, pointing to unperceived barriers. The most frequently reported barriers were self-reliance ("wanted to deal with the problem alone", 18.4\%), perceived ineffectiveness of treatment ("did not think that treatment might help", $8.7 \%$ ), unavailability (8.3\%) and treatment stigma ("afraid what people would think about me being in treatment", 6.7\%). Financial and insurance-related barriers were comparatively rare (1.1\%). Interestingly, help-seekers more frequently perceived treatment barriers than nonseekers $\left(40.9 \%\right.$ vs. $\left.27.8 \%, \chi^{2}(1)=9.86, p=0.022\right)$. The frequency of specific barriers did not differ in help-seekers vs. non-seekers, and the number of perceived barriers 
Table 3 Predictors of 12-month help-seeking in individuals with $\mathrm{AD}$

\begin{tabular}{|c|c|c|c|c|c|c|}
\hline & \multirow[t]{2}{*}{$\mathrm{N}$} & \multirow{2}{*}{$\begin{array}{l}\text { Proportion of } \\
\text { help-seekers }^{\mathrm{a}} \\
\%\end{array}$} & \multicolumn{4}{|c|}{ Association of predictors with help-seeking } \\
\hline & & & OR & CI $95 \%$ & & $\mathrm{p}$ \\
\hline \multicolumn{7}{|c|}{ Sociodemographic factors } \\
\hline \multicolumn{7}{|c|}{ Gender } \\
\hline Women & 453 & 16.9 & Ref. & & & \\
\hline Men & 190 & 14.1 & 0.83 & 0.44 & 1.54 & 0.553 \\
\hline \multicolumn{7}{|l|}{ Age } \\
\hline $18-34$ & 146 & 21.1 & 1.33 & 0.64 & 2.77 & 0.442 \\
\hline $35-49$ & 178 & 16.3 & 0.99 & 0.50 & 1.94 & 0.967 \\
\hline $50-64$ & 196 & 16.6 & Ref. & & & \\
\hline $65-79$ & 123 & 4.5 & 0.24 & 0.07 & 0.76 & 0.015 \\
\hline \multicolumn{7}{|l|}{ Current partnership } \\
\hline Yes & 454 & 13.1 & Ref. & & & \\
\hline No & 189 & 23.1 & 1.93 & 1.01 & 3.72 & 0.048 \\
\hline \multicolumn{7}{|l|}{ Educational level } \\
\hline Low & 190 & 16.7 & 1.28 & 0.64 & 2.56 & 0.488 \\
\hline Medium & 345 & 17.0 & Ref. & & & \\
\hline High & 106 & 9.8 & 0.58 & 0.22 & 1.48 & 0.251 \\
\hline \multicolumn{7}{|l|}{ SES } \\
\hline Low & 118 & 16.6 & 0.93 & 0.44 & 1.95 & 0.849 \\
\hline Medium & 392 & 17.2 & Ref. & & & \\
\hline High & 131 & 10.8 & 0.56 & 0.26 & 1.20 & 0.135 \\
\hline \multicolumn{7}{|l|}{ Enabling factors } \\
\hline \multicolumn{7}{|l|}{ Employment } \\
\hline Yes & 360 & 12.7 & Ref. & & & \\
\hline No & 283 & 20.6 & 2.62 & 1.41 & 4.85 & 0.002 \\
\hline \multicolumn{7}{|l|}{ Urbanization } \\
\hline$<20 \mathrm{~T}$ inhibitants & 108 & 17.8 & 0.93 & 0.41 & 2.15 & 0.872 \\
\hline $20-100 \mathrm{~T}$ & 142 & 19.1 & 1.06 & 0.49 & 2.29 & 0.882 \\
\hline $100-500 \mathrm{~T}$ & 183 & 9.9 & 0.46 & 0.22 & 0.97 & 0.040 \\
\hline$>500 \mathrm{~T}$ & 210 & 18.9 & Ref. & & & \\
\hline \multicolumn{7}{|l|}{ Need factors } \\
\hline \multicolumn{7}{|l|}{ Disability } \\
\hline No & 418 & 5.4 & Ref. & & & \\
\hline Yes & 225 & 32.7 & 8.11 & 4.35 & 15.10 & 0.000 \\
\hline \multicolumn{7}{|l|}{ Chronicity } \\
\hline $0-5$ years & 418 & 10.9 & Ref. & & & \\
\hline $6-20$ years & 116 & 24.8 & 2.60 & 1.25 & 5.42 & 0.011 \\
\hline$>20$ years & 109 & 25.6 & 3.60 & 1.77 & 7.32 & 0.000 \\
\hline \multicolumn{7}{|l|}{ Number of AD } \\
\hline 1 & 492 & 8.5 & Ref. & & & \\
\hline 2 & 105 & 23.6 & 3.49 & 1.71 & 7.13 & 0.001 \\
\hline $3+$ & 46 & 67.89 & 23.70 & 10.39 & 54.05 & 0.000 \\
\hline \multicolumn{7}{|l|}{ Comorbid depression } \\
\hline No & 491 & 11.3 & Ref. & & & \\
\hline Yes & 152 & 30.2 & 3.32 & 1.81 & 6.12 & 0.000 \\
\hline
\end{tabular}

Predictors were entered separately into the logistic regression model. All analyses adjusted for sex and age group. Bold values indicate significant ORs

$\mathrm{SES}=$ socio-economic status, $\mathrm{AD}=$ anxiety disorder, $\mathrm{OR}=$ odds ratio, $\mathrm{CI}=$ confidence interval, $\mathrm{p}=\mathrm{p}$-value

${ }^{a}$ Among individuals with given predictors 
Table 4 Characteristics of lifetime specialized outpatient treatments

\begin{tabular}{|c|c|c|c|c|}
\hline & \multicolumn{2}{|c|}{ Psychiatrist $(\mathrm{N}=59)$} & \multicolumn{2}{|c|}{$\begin{array}{l}\text { Psychothera- } \\
\text { pist }(\mathrm{N}=55)\end{array}$} \\
\hline & $\mathrm{N}$ & $\%$ & $\mathrm{~N}$ & $\%$ \\
\hline \multicolumn{5}{|l|}{ Number of sessions } \\
\hline $1-5$ & 21 & 38.1 & 8 & 21.4 \\
\hline $6-30$ & 19 & 28.7 & 16 & 16.4 \\
\hline $31-59$ & 7 & 13.6 & 12 & 24.1 \\
\hline$\geq 60$ & 9 & 14.4 & 17 & 34.2 \\
\hline \multicolumn{5}{|l|}{ Duration of sessions } \\
\hline $1-10 \mathrm{~min}$ & 11 & 18.7 & 1 & 1.1 \\
\hline $11-30 \mathrm{~min}$ & 35 & 61.7 & 3 & 11.9 \\
\hline $31-49 \min$ & 6 & 6.8 & 5 & 5.6 \\
\hline $50 \mathrm{~min}$ & 6 & 10.8 & 45 & 80.3 \\
\hline \multicolumn{5}{|l|}{ Duration of therapy } \\
\hline Up to one year & 18 & 25.8 & 16 & 27.2 \\
\hline $1-3$ years & 8 & 13.9 & 20 & 41.2 \\
\hline$>3$ years & 33 & 60.3 & 13 & 31.6 \\
\hline \multicolumn{5}{|l|}{ Type of treatment } \\
\hline Medication & 43 & 76.9 & 6 & 12.8 \\
\hline CBT & 2 & 2.6 & 20 & 29.7 \\
\hline Other psychotherapy & 36 & 56.2 & 37 & 70.1 \\
\hline Group therapy & 0 & 0.0 & 3 & 2.1 \\
\hline Other treatment & 8 & 10.6 & 3 & 5.6 \\
\hline \multicolumn{5}{|l|}{ Satisfaction with therapy } \\
\hline (Rather) satisfied & 26 & 42.8 & 31 & 56.3 \\
\hline Partly satisfied & 23 & 43.0 & 18 & 35.4 \\
\hline Dissatisfied & 10 & 14.2 & 6 & 8.3 \\
\hline
\end{tabular}

$\mathrm{CBT}=$ cognitive behavioral therapy

(categorized to one, two, three, more than three) was not associated with help-seeking $(O R=1.49, C I=0.91-2.43$, $d f_{\text {model }}=186$ ). Of the specific barriers, only self-reliance was associated with help-seeking $(O R=2.88$, $C I=1.15-7.20, d f_{\text {model }}=186$ ).

Regarding specific $\mathrm{AD}$, cases with PD most frequently had considered seeking help (81.8\%), compared to $58.4 \%$ and $34.6 \%$ of SPEC without comorbid AD. Treatment barriers were most frequently reported in GAD $(46.6 \%)$ and least frequently in SPEC (28.2\%). Overall, the ranking of different barriers was comparable between diagnoses. By visual inspection, cases with PD more frequently reported perceived ineffectiveness of treatment, while cases with SAD were more frequently deterred by social consequences of seeking treatment (stigma, hospitalization), and cases with GAD less frequently reported self-reliance.

\section{Treatment Dropout}

Of the 187 cases with lifetime help-seeking, 27.2\% ( $\mathrm{N}=43)$ reported discontinuation of at least one mental health treatment. Among those, the most frequent dropout reasons were negative experiences with the provider (i.e., did not get along with provider, $47.1 \%$, or felt mistreated, $11.7 \%$ ), negative experiences with treatment (i.e. felt out of place, $14.9 \%$, could not manage treatment demands, $12.2 \%$, or negative side effects, $10.6 \%$ ), and perceived ineffectiveness of treatment $(26.9 \%)$. Stigma (2.1\%) and social pressure from others (1.8\%) were rarely a reason for discontinuation (see Fig. 1). Notably, $47.9 \%$ of cases with dropout were still receiving disorder-specific interventions during the last 12 months.

\section{Discussion}

Based on a representative community sample of the German adult population, we found that only $26 \%$ of all cases with a 12-month diagnosis of $\mathrm{AD}$ received any intervention for anxiety problems in their lifetime. In reference to the past 12 months, only $13 \%$ received a disorder-specific intervention of any type, irrespective of its adequacy in terms of type, duration and frequency.

\section{Treatment Barriers}

Overall, $40 \%$ of the sample never considered seeking help. Moreover, most non-seekers (72\%) did not experience barriers to treatment, but simply had never thought about seeking help. The main explicit barriers were self-reliance (wanting to deal with the problem alone; 18\%) and assumed ineffectiveness of treatments (9\%). A potential explanation of these major barriers might be limited health literacy. Mental health literacy refers to the amount of knowledge and beliefs about mental disorders, including the ability to recognize specific disorders and knowing where to seek help (Jorm et al. 1997). There is evidence for relatively low public health literacy concerning AD. For example, in a case vignette study by Coles et al. (2014) among US adults, less than half of the anxiety vignettes were identified as mental disorders, compared to $62 \%$ for a depression vignette, and less than $20 \%$ were able to name the $\mathrm{AD}$, compared to more than $50 \%$ for depression. Even among psychology students, only a minority were able to identify AD symptoms as indicating a mental disorder (Coles and Coleman 2010). Thus, the inability to recognize anxiety symptoms as mental health problems might be a major reason for not seeking help. Another potential problem is limited knowledge about and/or low trust in the mental health care system. Indeed, there is evidence for lower public trust in healthcare institutions in Germany compared to other western European states (van der Schee et al. 2007) and the moderate satisfaction with treatments in our sample might also point in this direction. 
Table 5 Frequency of treatment barriers among individuals with $\mathrm{AD}$

\begin{tabular}{|c|c|c|c|c|c|c|c|c|c|c|c|c|}
\hline & \multicolumn{2}{|c|}{ Any AD } & \multicolumn{2}{|l|}{ PD } & \multicolumn{2}{|l|}{ AG } & \multicolumn{2}{|c|}{ SAD } & \multicolumn{2}{|c|}{ GAD } & \multicolumn{2}{|c|}{ SPEC } \\
\hline & $\mathrm{N}$ & $\%$ & $\mathrm{~N}$ & $\%$ & $\mathrm{~N}$ & $\%$ & $\mathrm{~N}$ & $\%$ & $\mathrm{~N}$ & $\%$ & $\mathrm{~N}$ & $\%$ \\
\hline Thought about seeking help & 365 & 60.1 & 77 & 81.8 & 114 & 70.1 & 74 & 79.7 & 60 & 76.4 & 218 & 58.4 \\
\hline Perceived any barrier & 187 & 31.3 & 33 & 33.9 & 53 & 28.5 & 42 & 40.8 & 31 & 46.6 & 114 & 28.2 \\
\hline Wanted to deal with problem alone & 113 & 18.4 & 22 & 24.8 & 32 & 15.7 & 29 & 25.7 & 15 & 23.6 & 68 & 17.0 \\
\hline Perceived ineffectiveness & 52 & 8.7 & 11 & 14.0 & 14 & 6.9 & 14 & 13.8 & 10 & 11.7 & 31 & 7.8 \\
\hline Unavailability & 48 & 8.3 & 10 & 10.9 & 16 & 9.0 & 12 & 12.6 & 10 & 15.7 & 28 & 6.9 \\
\hline Waiting time too long & 27 & 5.5 & 7 & 9.3 & 10 & 6.5 & 7 & 9.6 & 5 & 8.5 & 15 & 4.6 \\
\hline Problems with transport/timing & 14 & 2.7 & 3 & 5.1 & 2 & 1.6 & 4 & 5.0 & 3 & 5.4 & 8 & 2.0 \\
\hline Did not get an appointment & 10 & 2.2 & 1 & 2.8 & 4 & 1.8 & 6 & 7.4 & 2 & 3.3 & 5 & 2.0 \\
\hline Did not find a provider & 12 & 1.3 & 3 & 1.8 & 4 & 1.6 & 3 & 2.5 & 2 & 2.5 & 9 & 1.5 \\
\hline Afraid of stigma & 34 & 6.7 & 7 & 8.3 & 12 & 7.3 & 13 & 13.7 & 6 & 8.7 & 18 & 5.9 \\
\hline Problems with professional & 26 & 4.3 & 7 & 7.0 & 9 & 6.2 & 6 & 5.4 & 1 & 2.6 & 17 & 4.4 \\
\hline Did not like p. & 16 & 2.7 & 4 & 2.5 & 5 & 4.1 & 3 & 2.1 & 1 & 2.6 & 9 & 2.1 \\
\hline P. did not take enough time & 7 & 1.4 & 2 & 4.3 & 4 & 3.0 & 2 & 3.2 & 0 & 0.0 & 6 & 2.1 \\
\hline P. did not see need for treatment & 5 & 0.5 & 1 & 0.3 & 2 & 0.4 & 1 & 0.2 & 0 & 0.0 & 3 & 0.6 \\
\hline Afraid of hospitalization & 11 & 1.9 & 3 & 3.3 & 5 & 3.0 & 5 & 5.0 & 0 & 0.0 & 8 & 2.3 \\
\hline Financial & 6 & 1.1 & 3 & 4.7 & 2 & 0.8 & 2 & 3.3 & 0 & 0.0 & 5 & 1.3 \\
\hline
\end{tabular}

$\mathrm{AD}=$ anxiety disorder, $\mathrm{PD}=$ panic disorder, $\mathrm{AG}=$ agoraphobia, $\mathrm{SAD}=$ social anxiety disorder, $\mathrm{GAD}=$ generalized anxiety disorder, $\mathrm{SPEC}=$ specific phobia
Fig. 1 Reasons for dropout among individuals with prior treatment discontinuation $(\mathrm{N}=43)$

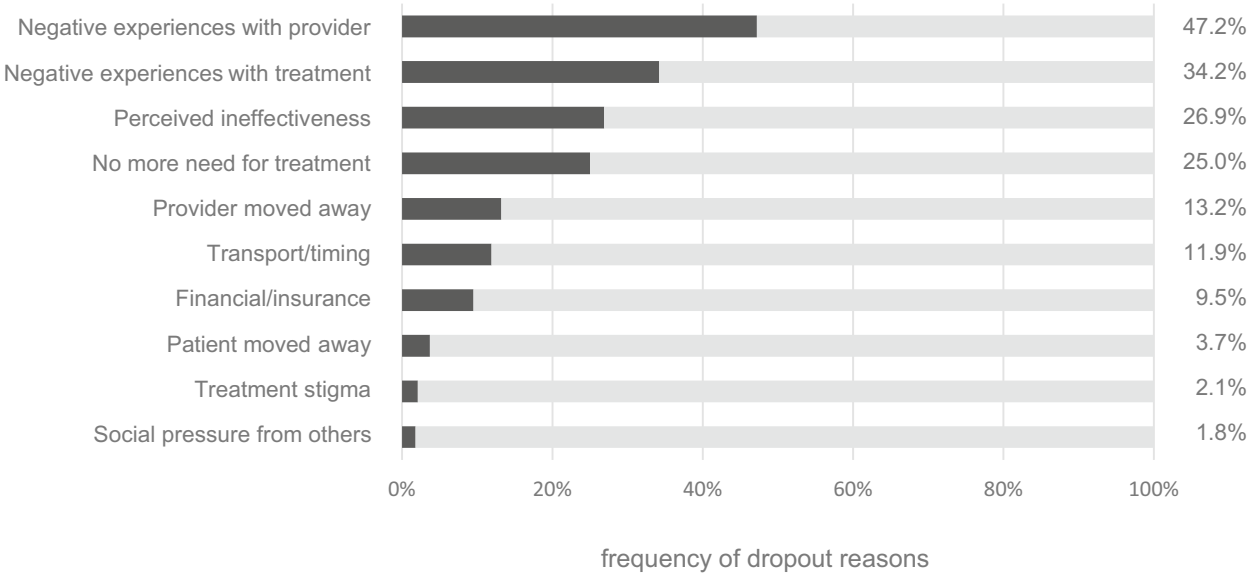

Another relevant barrier was reduced availability of formal help $(8 \%)$, driven primarily by long waiting periods. The average waiting time for outpatient psychological treatment in Germany is 20 weeks (Federal Psychotherapists' Chamber 2018) and can be longer for specialized treatments. Long waiting periods reduce the chance to receive treatment in a timely manner and can speak against the use of psychotherapy in acute cases (Bandelow et al. 2014). A third type of relevant barriers was perceived treatment stigma (7\%). Stigma has already been found associated with help-seeking, also in $\mathrm{AD}$ and specifically in young people (Calear et al. 2020; Clark et al. 2018). Clement et al. (2015) developed a comprehensive model of stigma and help-seeking and conclude that treatment stigma and internalized stigma (shame/ embarrassment) are most closely related to help-seeking. Such forms of stigma were not explicitly raised in this study and may underlie some of the prominent "I do not need any help" attitudes in our sample. Noticeably, 
financial barriers and limited scope of treatment time played a minor role in this population.

Taken together, our findings may indicate that some barriers (financial, basic availability of providers) have already been successfully targeted in the German population, whereas others are still prominent. These are a lack of awareness and, supposedly, mental health literacy for anxiety symptoms and treatments, delayed availability of treatments, and stigma-related barriers.

\section{Type of Help-Seeking}

Among those who crossed the Rubicon to seek formal help for their $\mathrm{AD}$, psychiatrists and psychotherapists were the most frequently used providers. This is encouraging, as psychiatrists and psychotherapists are supposed to be the qualified specialists for diagnostics and treatment of AD. Several points however raise further questions: First, $40 \%$ of psychiatric and $20 \%$ of psychotherapeutic patients reported only a maximum of five contacts. These patients likely did not get a minimally adequate treatment (Fernández et al. 2007). Second, CBT is the first-line treatment for AD, but only a minority of patients treated by psychotherapists (30\%) recall to have received CBT. Third, the majority of cases underwent long-term treatments, whereas treatment studies show that $\mathrm{AD}$ are treatable within 20-30 sessions (e.g., Lang et al. 2012), and that major effects are unlikely to occur late in therapy (Cuijpers et al. 2013). Note that the treatment characteristics data must be interpreted with caution. First, only a subsample of $n=92$ out of 155 cases answered the interview module on treatment characteristics. Also, this module set rather high demands on participants' memory and health literacy (what kind of treatment, how many sessions), especially for cases with complex service use histories. Reliability of these data might therefore be limited compared to the rest of the survey. Yet, as detailed information on treatment characteristics are rare in the literature, we chose to subjoin these data.

Remarkably, about half of all patients treated by psychiatrists or psychotherapists were partially or predominantly unsatisfied with their treatment. Dissatisfied patients were also more likely to report treatment dropout. This suggests that in many cases patients' expectations were not sufficiently met during treatment (Santana and Fontenelle 2011) Further investigations might examine patient expectations as a potential target to prevent dissatisfaction and dropout.

Help-seeking also differed substantially across the AD. In $\mathrm{PD}, \mathrm{SAD}$, and $\mathrm{GAD}$, around $40 \%$ currently received any kind of disorder-specific intervention, dropping to only $23 \%$ in cases with AG and $4 \%$ in cases with SPEC. Phobic disorders are thus the most prevalent but also least treated AD, despite efficient and effective treatments available (Zlomke and Davis 2008). Acknowledging that the diagnosis of a mental disorder per se does not imply a need for treatment, this finding is still in sharp contrast to the direct and free access to providers in highly developed mental health care systems such as that in Germany. Diagnosis-specific differences in help-seeking behavior might also reflect the public interest in different disorders. For PD and SAD, large-scale psychotherapy research efforts have been undertaken during the past years (Gloster et al. 2011; Leichsenring et al. 2009), efforts that do not appear to have been made for all AD. Interestingly, the number of used services was highest in SAD, whereas PD and GAD are traditionally seen as conditions with high utilization. This may be explained by the relative intense disability, persistence and overall comorbidity, which, in the German community, seems to be higher in SAD than in other AD.

The help-seeking estimates found here were lower than those reported by others (Bijl and Ravelli 2000; Mack et al. 2014; Mojtabai et al. 2002), but comparable to studies that examined disorder-specific help-seeking (Mackenzie et al. 2012). This reflects that not all cases with any service use also address their anxiety problems. In our sample, this concerns around one third of cases. The gap is largest in SPEC, where only $4 \%$ out of $19 \%$ with service use also addressed their anxiety, and is virtually nonexistent in PD and GAD (note however, that somatic symptoms of PD and GAD are often misattributed by providers, Wittchen et al. 2002, and see limitations for SPEC). Another reason for the low help-seeking rates could be the use of informal sources, esp. friends and family. Brown et al. (2014) found informal helpseeking to be more prevalent than formal help-seeking in common mental disorders. This is also specifically reported for older individuals, among whom symptoms of AD were not associated with formal help-seeking at all (Hohls et al. 2020).

\section{Predictors of Help-Seeking}

In line with other studies, the strongest predictors of helpseeking were mental-disorder-caused disability and the number of AD (Michel et al. 2018; Reavley et al. 2010; Roness et al. 2005). Strikingly, only $9 \%$ of cases with one AD sought help, compared to $68 \%$ of cases with three or more AD. This may reflect a tendency to seek help only at a late stage of disorder exacerbation, and may partly explain the high number of long-term psychotherapies. Individuals were also more prone to seek help if they were not in a partnership or were currently unemployed (cf. Roberts et al. 2018). Individuals who are socially integrated may rather rely on informal sources of help (partner, colleagues). The finding that older individuals (65-79 years) were less likely to seek help is consistent with previous findings on AD (Mackenzie et al. 2012), but in contrast with other mental disorders, where 
lower treatment rates are seen in younger adults (Mack et al. 2014; Rickwood et al. 2005). Possibly, anxiety symptoms such as palpitations are often attributed to somatic disorders in older adults, or anxiety symptoms are cared for en passant by GPs (Hohls et al. 2019). This finding therefore calls for more rigorous attention to $\mathrm{AD}$ in older adults.

\section{Treatment Dropout}

Finally, $28 \%$ of help-seekers reported to have already discontinued a mental health treatment, mainly due to negative experiences with providers or applied treatments. This is consistent with the relatively high proportion of dissatisfied patients in our sample. Some patients may enroll in different health services but successfully complete only a few, given the high number of different providers and variety of health services. This interpretation is supported by the fact that $40 \%$ of the dropouts were still in treatment by the time of the survey. In sum, dissatisfaction and treatment dropout are frequent among AD patients. Providers should thus be sensitive to thematize prior and current negative experiences during treatment.

\section{Limitations}

Limitations included, first, that we used cross-sectional data, preventing straightforward causal inferences. Second, we examined 12-month AD, whereas individuals with former, now remitted episodes of AD were not included. This resulted in a high mean age of onset $(M=36.7, S D=18.6)$. Third, 12-month use of inpatient services may have been underestimated because hospitalized individuals were not recruited for the survey. Fourth, we relied on participants' self-report, which is subject to memory bias. For example, some help-seekers may not be aware whether they saw a psychiatrist, psychotherapist, or other medical practitioner. Fifth, $27 \%$ of the sample had multiple AD, which may have blurred the distinctions between disorders. Sixth, we did not differentiate primary AD and AD secondary to other problems, which may explain partly why individuals did not seek help due to symptoms of anxiety. Seventh, the item to examine disorder-specific help-seeking for SPEC differed from the other AD (open vs. closed question, see methods) which may have diminished help-seeking percentages in phobias. However, estimates of general service use, that were not biased by the type of question, were also substantially lower in SPEC (Supplement B). Finally, to detect help-seekers we asked participants whether they had ever talked to a professional about their AD. It is therefore possible that participants had used mental health services due to their AD before (mean duration of AD was 8.5 years), but only for other reasons in the last 12 months. This may have resulted in overestimated 12-month help-seeking percentages.

\section{Implications}

Our results confirm that help-seeking for AD in Germany is low, despite access to a well-developed healthcare system. Help-seeking seems to be hampered primarily by unawareness, the belief to manage the problems alone and perceived ineffectiveness of treatments. Interventions targeting mental health literacy (Gulliver et al. 2012) are thus needed to inform the public about the symptoms, treatable nature and types of interventions for AD, to decrease stigma and to generate realistic expectations towards mental health and mental health treatments. Large-scale awareness campaigns have been launched for depression and suicidality (Hegerl et al. 2008; Paykel et al. 1998), but not for AD. Other streams of interventions might include training of outpatient therapists and psychiatrists, who carry the brunt of treatment, to apply evidence-based interventions such as exposure (Harned et al. 2014), and the removal of structural barriers perceived by therapists (Pittig et al. 2019). Our results also show that those who seek help do not necessarily talk to their GP, who is commonly supposed to assign appropriate interventions. Thus, providers should continue to engage in active collaboration across service sectors to help patients in finding the most suitable treatment.

Acknowledgements DEGS1-MH is a project by the Robert Koch Institute (Berlin, Germany; head of the Department of Epidemiology and Health Monitoring: Dr. Bärbel-Maria Kurth) funded primarily by the German Ministry of Health (BMG; 1368-1124). Supplementary funding is provided by the Technische Universität Dresden, and by the Stiftung Seelische Gesundheit inaugurated by the German Association for Psychiatry and Psychotherapy (DGPPN) for implementation of neurocognitive assessment and for extending the psychosis section (Prof. Dr. Wolfgang Maier, Prof. Dr. Wolfgang Gaebel). We would like to acknowledge the support of all RKI staff in the field work of the project and the many staff members and interviewers of DEGS1$\mathrm{MH}$ at Technische Universität Dresden. We also wish to thank all the DEGS1-MH study participants.

Funding Open Access funding enabled and organized by Projekt DEAL.

\section{Compliance with ethical standards}

Conflict of Interest The authors declare that they have no conflict of interest.

Ethical Standards The study proposal, field procedures, and information for respondents of DEGS1 were approved by the Medical Ethics Review Committees responsible for DEGS1 (Charité, Berlin) and for DEGS1-MH by the Ethics Board of the Technische Universität Dresden, respectively. The study has been performed in accordance with the ethical standards laid down in the 1964 Declaration of Helsinki and its later amendments. All participants gave written informed consent prior 
to their inclusion in the study. All authors certify their responsibility for the present manuscript.

Open Access This article is licensed under a Creative Commons Attribution 4.0 International License, which permits use, sharing, adaptation, distribution and reproduction in any medium or format, as long as you give appropriate credit to the original author(s) and the source, provide a link to the Creative Commons licence, and indicate if changes were made. The images or other third party material in this article are included in the article's Creative Commons licence, unless indicated otherwise in a credit line to the material. If material is not included in the article's Creative Commons licence and your intended use is not permitted by statutory regulation or exceeds the permitted use, you will need to obtain permission directly from the copyright holder. To view a copy of this licence, visit http://creativecommons.org/licenses/by/4.0/.

\section{References}

Alonso, J., Angermeyer, M. C., Bernert, S., Bruffaerts, R., Brugha, T. S., Bryson, H., et al. (2004a). Disability and quality of life impact of mental disorders in Europe: Results from the European Study of the Epidemiology of Mental Disorders (ESEMeD) project. Acta Psychiatrica Scandinavica, 104(suppl. 420), 38-46. https://doi. org/10.1111/j.1600-0047.2004.00329.x.

Alonso, J., Angermeyer, M. C., Bernert, S., Bruffaerts, R., Brugha, T. S., Bryson, H., et al. (2004b). Use of mental health services in Europe: Results from the European Study of the Epidemiology of Mental Disorders (ESEMeD) project. Acta Psychiatrica Scandinavica, 109(suppl. 420), 47-54. https://doi.org/10.111 1/j.1600-0047.2004.00330.x.

Asp, M., Lindqvist, D., Fernström, J., Ambrus, L., Tuninger, E., Reis, M., \& Westrin, A. (2020). Recognition of personality disorder and anxiety disorder comorbidity in patients treated for depression in secondary psychiatric care. PLoS ONE, 15(1), 1-15. https://doi. org/10.1371/journal.pone.0227364.

Bandelow, B., Wiltink, J., Alpers, G. W., Benecke, C., Deckert, J., Eckhardt-Henn, A., et al. (2014). Deutsche S3-Leitlinie zur Behandlung von Angststörungen. Retrieved from www.awmf.org/leitl inien.htm

Bélanger, C., Courchesne, C., Leduc, A. G., Dugal, C., El-Baalbaki, G., Marchand, A., et al. (2017). Predictors of dropout from cognitive-behavioral group treatment for panic disorder with agoraphobia. Behavior Modification, 41(1), 113-140. https://doi. org/10.1177/0145445516656614.

Bijl, R. V., \& Ravelli, A. (2000). Psychiatric morbidity, service use, and need for care in the general population: Results of the Netherlands Mental Health Survey and Incidence Study. American Journal of Public Health, 90(4), 602-607. https://doi.org/10.2105/ AJPH.90.4.602.

Brown, J. S. L., Evans-Lacko, S., Aschan, L., Henderson, M. J., Hatch, S. L., \& Hotopf, M. (2014). Seeking informal and formal help for mental health problems in the community: A secondary analysis from a psychiatric morbidity survey in South London. BMC Psychiatry, 14, 275-290. https://doi.org/10.1186/s12888-014-0275-y.

Butler, A. C., Chapman, J. E., Forman, E. M., \& Beck, A. T. (2006). The empirical status of cognitive-behavioral therapy: A review of meta-analyses. Clinical Psychology Review, 26(1), 17-31. https:// doi.org/10.1016/j.cpr.2005.07.003.

Calear, A. L., Batterham, P. J., Torok, M., \& McCallum, S. (2020). Help-seeking attitudes and intentions for generalised anxiety disorder in adolescents: The role of anxiety literacy and stigma. European Child and Adolescent Psychiatry. https://doi. org/10.1007/s00787-020-01512-9.

Carpenter, J. K., Andrews, L. A., Witcraft, S. M., Powers, M. B., Smits, J. A. J., \& Hofmann, S. G. (2018). Cognitive behavioral therapy for anxiety and related disorders: A meta-analysis of randomized placebo-controlled trials. Depression and Anxiety, 35(6), 502514. https://doi.org/10.1002/da.22728.

Clark, L. H., Hudson, J. L., Dunstan, D. A., \& Clark, G. I. (2018). Barriers and facilitating factors to help-seeking for symptoms of clinical anxiety in adolescent males. Australian Journal of Psychology, 70(3), 225-234. https://doi.org/10.1111/ajpy.12191.

Clement, S., Schauman, O., Graham, T., Maggioni, F., Evans-Lacko, S., Bezborodovs, N., et al. (2015). What is the impact of mental health-related stigma on help-seeking? A systematic review of quantitative and qualitative studies. Psychological Medicine, 45(1), 11-27. https://doi.org/10.1017/S0033291714000129.

Coles, M. E., \& Coleman, S. L. (2010). Barriers to treatment seeking for anxiety disorders: Initial data on the role of mental health literacy. Depression and Anxiety, 27, 63-71. https://doi.org/10.1002/ da. 20620

Coles, M. E., Schubert, J. R., Heimberg, R. G., \& Weiss, B. D. (2014). Disseminating treatment for anxiety disorders: Step 1: Recognizing the problem as a precursor to seeking help. Journal of Anxiety Disorders, 28(8), 737-740. https://doi.org/10.1016/j.janxd is.2014.07.011

Cuijpers, P., Sijbrandij, M., Koole, S. L., Andersson, G., Beekman, A. T., \& Reynolds, C. F. (2013). The efficacy of psychotherapy and pharmacotherapy in treating depressive and anxiety disorders: A meta-analysis of direct comparisons. World Psychiatry, 12(2), 137-148. https://doi.org/10.1002/wps.20038.

De Graaf, R., Ten Have, M., Van Gool, C., \& Van Dorsselaer, S. (2012). Prevalence of mental disorders and trends from 1996 to 2009. Results from the Netherlands Mental Health Survey and Incidence Study-2. Social Psychiatry and Psychiatric Epidemiology, 47(2), 203-213. https://doi.org/10.1007/s00127-010-0334-8.

Essau, C. A. (2005). Frequency and patterns of mental health services utilization among adolescents with anxiety and depressive disorders. Depression and Anxiety. https://doi.org/10.1002/da.20115.

Federal Psychotherapists' Chamber. (2018). Wartezeiten 2018-Ein Jahr nach der Reform der Psychotherapie-Richtlinie. Retrieved from https://www.bptk.de/wp-content/uploads/2019/01/20180 411_bptk_studie_wartezeiten_2018.pdf

Fernández, A., Haro, J. M., Martinez-Alonso, M., Demyttenaere, K., Brugha, T. S., Autonell, J., et al. (2007). Treatment adequacy for anxiety and depressive disorders in six European countries. British Journal of Psychiatry, 190, 172-173. https://doi.org/10.1192/ bjp.bp.106.023507.

Fernandez, E., Salem, D., Swift, J. K., Ramtahal, N., Fernandez, E., Salem, D., et al. (2015). Meta-analysis of dropout from cognitive behavioral therapy. Journal of Consulting and Clinical Psychology, 83(6), 1108-1122. https://doi.org/10.1037/ccp0000044.

Gloster, A. T., Wittchen, H.-U., Einsle, F., Lang, T., Helbig-Lang, S., Fydrich, T., et al. (2011). Psychological treatment for panic disorder with agoraphobia: A randomized controlled trial to examine the role of therapist-guided exposure in situ in CBT. Journal of Consulting and Clinical Psychology, 79(3), 406-420. https://doi. org/10.1037/a0023584.

Goodwin, R., \& Andersen, R. M. (2002). Use of the behavioral model of health care use to identify correlates of use of treatment for panic attacks in the community. Social Psychiatry and Psychiatric Epidemiology, 37(5), 212-219. https://doi.org/10.1007/s0012 7-002-0543-x.

Gulliver, A., Griffiths, K. M., Christensen, H., \& Brewer, J. L. (2012). A systematic review of help-seeking interventions for depression, anxiety and general psychological distress. BMC Psychiatry. https ://doi.org/10.1186/1471-244X-12-81. 
Gustavsson, A., Svensson, M., Jacobi, F., Allgulander, C., Alonso, J., Beghi, E., et al. (2011). Cost of disorders of the brain in Europe 2010. European Neuropsychopharmacology, 21(10), 718-779. https://doi.org/10.1016/j.euroneuro.2011.08.008.

Harned, M. S., Dimeff, L. A., Woodcock, E. A., Kelly, T., Zavertnik, J., Contreras, I., \& Danner, S. M. (2014). Exposing clinicians to exposure: A randomized controlled dissemination trial of exposure therapy for anxiety disorders. Behavior Therapy, 45(6), 731-744. https://doi.org/10.1016/j.beth.2014.04.005.

Hegerl, U., Wittmann, M., Arensman, E., van Audenhove, C., Bouleau, J.-H., van der Feltz-Cornelis, C., et al. (2008). The 'European Alliance Against Depression (EAAD)': A multifaceted, community-based action programme against depression and suicidality. The World Journal of Biological Psychiatry, 9(1), 51-58. https:// doi.org/10.1080/15622970701216681.

Hohls, J. K., König, H.-H., Eisele, M., Mallon, T., Mamone, S., Wiese, B., et al. (2020). Help-seeking for psychological distress and its association with anxiety in the oldest old-results from the AgeQualiDe cohort study. Aging \& Mental Health. https://doi. org/10.1080/13607863.2020.1725737.

Hohls, J. K., König, H. H., van den Bussche, H., Eisele, M., Wiese, B., Oey, A., et al. (2019). Association of anxiety symptoms with health care use and costs in people aged 85 and over. International Journal of Geriatric Psychiatry, 34(5), 765-776. https:// doi.org/10.1002/gps.5089.

Jacobi, F., Höfler, M., Siegert, J., Mack, S., Gerschler, A., Scholl, L., et al. (2014). Twelve-month prevalence, comorbidity and correlates ofmental disorders in Germany: The Mental Health Module of the German Health Interview and Examination Survey for Adults (DEGS1-MH). International Journal of Methods in Psychiatric Research, 23(3), 304-319. https://doi.org/10.1002/mpr.

Jacobi, F., Mack, S., Gerschler, A., Scholl, L., Höfler, M., Siegert, J., et al. (2013). The design and methods of the mental health module in the German Health Interview and Examination Survey for Adults (DEGS1-MH). International Journal of Methods in Psychiatric Research, 22(2), 83-99.

Jacobi, F., Wittchen, H.-U., Hölting, C., Höfler, M., Pfister, H., Müller, N., \& Lieb, R. (2004). Prevalence, co-morbidity and correlates of mental disorders in the general population: Results from the German Health Interview and Examination Survey (GHS). Psychological Medicine, 34, 1-15 Retrieved from https://www.cambr idge.org/core/journals/psychological-medicine/article/prevalence -comorbidity-and-correlates-of-mental-disorders-in-the-generalpopulation-results-from-the-german-health-interview-and-exami nation-survey-ghs/811E40B225BCBAFC92ACDA234D90B333.

Jorm, A. F., Korten, A. E., Jacomb, P. A., Christensen, H., Rodgers, B., \& Pollitt, P. (1997). "Mental health literacy": A survey of the public's ability to recognise mental disorders and their beliefs about the effectiveness of treatment. Medical Journal of Australia, 166(4), 182-186.

Kamtsiuris, P., Lange, M., Hoffmann, R., Schaffrath Rosario, A., Dahm, S., Kuhnert, R., \& Kurth, B. M. (2013). Die erste Welle der Studie zur Gesundheit Erwachsener in Deutschland (DEGS1): Stichprobendesign, response, Gewichtung und Repräsentativität. Bundesgesundheitsblatt-Gesundheitsforschung-Gesundheitsschutz, 56(5-6), 620-630. https://doi.org/10.1007/s0010 3-012-1650-9.

Kessler, R. C., McGonagle, K. A., Zhao, S., Nelson, C. B., Hughes, M., Eshleman, S., et al. (1994). Lifetime and 12-month prevalence of DSM-III-R psychiatric disorders in the United States. Archives of General Psychiatry, 51(1), 8. https://doi.org/10.1001/ archpsyc.1994.03950010008002.

Kessler, R. C., Petukhova, M., Sampson, N. A., Zaslavsky, A. M., \& Wittchen, H.-U. (2012). Twelve-month and lifetime prevalence and lifetime morbid risk of anxiety and mood disorders in the United States. International Journal of Methods in Psychiatric
Research, 21(3), 169-184. https://doi.org/10.1002/mpr.1359. Twelve-month.

Kirmayer, L. J., Robbins, J. M., Dworkind, M., \& Yaffe, M. J. (1993). Somatization and the recognition of depression and anxiety in primary care. American Journal of Psychiatry, 150, 734-741. https ://doi.org/10.1176/ajp.150.5.734.

Konnopka, A., Leichsenring, F., Leibing, E., \& König, H.-H. (2009). Cost-of-illness studies and cost-effectiveness analyses in anxiety disorders: A systematic review. Journal of Affective Disorders, 114(1-3), 14-31. https://doi.org/10.1016/j.jad.2008.07.014.

Lang, T., Helbig-Lang, S., Westphal, D., Gloster, A. T., \& Wittchen, H.-U. (2012). Expositionsbasierte Therapie der Panikstörung mit Agoraphobie. Göttingen: Hogrefe.

Leichsenring, F., Hoyer, J., Beutel, M., Herpertz, S., Hiller, W., Irle, E., et al. (2009). The social phobia psychotherapy research network. Psychotherapy and Psychosomatics, 78(1), 35-41. https:// doi.org/10.1159/000162299.

Mack, S., Jacobi, F., Beesdo-Baum, K., Gerschler, A., Strehle, J., Höfler, M., et al. (2015). Functional disability and quality of life decrements in mental disorders: Results from the Mental Health Module of the German Health Interview and Examination Survey for Adults (DEGS1-MH). European Psychiatry, 30(6), 793-800. https://doi.org/10.1016/j.eurpsy.2015.06.003.

Mack, S., Jacobi, F., Gerschler, A., Strehle, J., Höfler, M., Busch, M. A., et al. (2014). Self-reported utilization of mental health services in the adult German population-evidence for unmet needs ? Results of the DEGS1-Mental Health Module (DEGS1-MH). International Journal of Methods in Psychiatric Research, 23(3), 289-303. https://doi.org/10.1002/mpr.

Mackenzie, C. S., Reynolds, K., Cairney, J., Streiner, D. L., \& Sareen, J. (2012). Disorder-specific mental health service use for mood and anxiety disorders: Associations with age, sex, and psychiatric comorbidity. Depression and Anxiety, 29(3), 234-242. https://doi. org/10.1002/da.20911.

Magee, W. J., Eaton, W. W., Wittchen, H.-U., McGonagle, K. A., Kessler, R. C., Magee, W. J., et al. (1996). Agoraphobia, simple phobia, and social phobia in the National Comorbidity Survey. Archives of General Psychiatry, 53(2), 159-168. https://doi. org/10.1001/archpsyc.1996.01830020077009.

Michel, C., Schnyder, N., Schmidt, S., Groth, N., Schimmelmann, B., \& Schultze-Lutter, F. (2018). Functioning mediates help-seeking for mental problems in the general population. European Psychiatry, 54, 1-9. https://doi.org/10.1016/j.eurpsy.2018.06.009.

Mojtabai, R., Olfson, M., \& Mechanic, D. (2002). Perceived need and help-seeking in adults with mood, anxiety, or substance use disorders. Archives of General Psychiatry, 59(1), 77-84. https://doi. org/10.1001/archpsyc.59.1.77.

Mojtabai, R., Olfson, M., Sampson, N. A., Jin, R., Druss, B., Wang, P. S., et al. (2011). Barriers to mental health treatment: Results from the National Comorbidity Survey Replication. Psychological Medicine, 41(8), 1751-1761. https://doi.org/10.1017/S0033 291710002291.

Norton, P. J., \& Price, E. C. (2007). A meta-analytic review of adult cognitive-behavioral treatment outcome across the anxiety disorders. The Journal of Nervous and Mental Disease, 195(6), 521-531. https://doi.org/10.1097/01.nmd.0000253843.70149.9a.

Olfson, M., Guardino, M., Struening, E., Schneier, F. R., Hellman, F., \& Klein, D. F. (2000). Barriers to the treatment of social anxiety. American Journal of Psychiatry, 157(4), 521-527. https://doi. org/10.1176/appi.ajp.157.4.521.

Paykel, E. S., Hart, D., \& Priest, R. G. (1998). Changes in public attitudes to depression during the Defeat Depression Campaign. British Journal of Psychiatry, 173(6), 519-522. https://doi. org/10.1192/bjp.173.6.519.

Pittig, A., Kotter, R., \& Hoyer, J. (2019). The struggle of behavioral therapists with exposure: Self-reported practicability, negative 
beliefs, and therapist distress about exposure-based interventions. Behavior Therapy, 50, 353-366 Retrieved from https://www.scien cedirect.com/science/article/pii/S000578941830087X.

Reavley, N. J., Cvetkovski, S., Jorm, A. F., \& Lubman, D. I. (2010). Help-seeking for substance use, anxiety and affective disorders among young people: Results from the 2007 Australian national survey of mental health and wellbeing. Australian and New Zealand Journal of Psychiatry, 44, 729-735. https://doi. org/10.3109/00048671003705458.

Reed, V., Gander, F., Pfister, H., Steiger, A., Holger Sonntag, C., Sonntag, A., et al. (1998). To what degree does the composite international diagnostic interview (CIDI) correctly identify DSM-IV disorders? testing validity issues in a clinical sample. International Journal of Methods in Psychiatric Research, 7(3), 142-155. https ://doi.org/10.1002/mpr.44.

Rickwood, D., Deane, F. P., Wilson, C. J., Ciarrochi, J., Rickwood, D., Deane, F. P., et al. (2005). Young people's help-seeking for mental health problems. Australian E-Journal for the Advancement of Mental Health, 4(3 (suppl.)), 218-251. https://doi.org/10.5172/ jamh.4.3.218.

Roberge, P., Fournier, L., Duhoux, A., Nguyen, C. T., \& Smolders, M. (2011). Mental health service use and treatment adequacy for anxiety disorders in Canada. Social Psychiatry and Psychiatric Epidemiology, 46(4), 321-330. https://doi.org/10.1007/s0012 7-010-0186-2.

Roberts, T., Miguel Esponda, G., Krupchanka, D., Shidhaye, R., Patel, V., \& Rathod, S. (2018). Factors associated with health service utilisation for common mental disorders: A systematic review. BMC Psychiatry, 18(1), 262. https://doi.org/10.1186/s1288 8-018-1837-1.

Roness, A., Mykletun, A., \& Dahl, A. A. (2005). Help-seeking behaviour in patients with anxiety disorder and depression. Acta Psychiatrica Scandinavica, 111, 51-58. https://doi.org/10.111 1/j.1600-0447.2004.00433.x.

Runge, A. J., Beesdo, K., Lieb, R., \& Wittchen, H.-U. (2008). Wie häufig nehmen jugendliche und junge erwachsene mit angststörungen eine psychotherapeutische behandlung in anspruch? Verhaltenstherapie, 18(1), 26-34. https://doi.org/10.1159/000113890.

Santana, L., \& Fontenelle, L. F. (2011). A review of studies concerning treatment adherence of patients with anxiety disorders. Patient Preference and Adherence, 5, 427-439. https://doi.org/10.2147/ PPA.S23439.

Scheidt-Nave, C., Kamtsiuris, P., Göwald, A., Hölling, H., Lange, M., Busch, M. A., et al. (2012). German health interview and examination survey for adults (DEGS) - Design, objectives and implementation of the first data collection wave. BMC Public Health, 12(1), 730. https://doi.org/10.1186/1471-2458-12-730.

StataCorp. (2017). Stata statistical software: Release 14. College Station, TX: StataCorp LLC.

Stein, M. B., Sherbourne, C. D., Craske, M. G., Means-Christensen, A., Bystritsky, A., Katon, W., et al. (2004). Quality of care for primary care patients with anxiety disorders. American Journal of Psychiatry, 161, 2230-2237. https://doi.org/10.1176/appi. ajp.161.12.2230

Taylor, S., Abramowitz, J. S., \& McKay, D. (2012). Non-adherence and non-response in the treatment of anxiety disorders. Journal of Anxiety Disorders, 26(5), 583-589. https://doi.org/10.1016/j. janxdis.2012.02.010.

van der Schee, E., Braun, B., Calnan, M., Schnee, M., \& Groenewegen, P. P. (2007). Public trust in health care: A comparison of Germany, The Netherlands, and England and Wales. Health Policy, 81(1), 56-67. https://doi.org/10.1016/j.healthpol.2006.04.004.

Wang, P. S., Aguilar-Gaxiola, S., Alonso, J., Angermeyer, M. C., Borges, G., Bromet, E. J., et al. (2007). Use of mental health services for anxiety, mood, and substance disorders in 17 countries in the WHO world mental health surveys. Lancet, 370(9590), 841-850. https://doi.org/10.1016/S0140-6736(07)61414-7.

Wang, P. S., Lane, M., Olfson, M., Pincus, H. A., Wells, K. B., \& Kessler, R. C. (2005). Twelve-month use of mental health services in the United States. Archives of General Psychiatry, 62(6), 629. https://doi.org/10.1001/archpsyc.62.6.629.

Wiltink, J., Haselbacher, A., Knebel, A., Tschan, R., Zwerenz, R., Michal, M., et al. (2010). Social phobia an anxiety disorder underdiagnosed in outpatient and consultation-liaison service? Psychotherapie, Psychosomatik Und Medizinische Psychologie, 60(3), 111-117. https://doi.org/10.1055/s-0029-1220692.

Wittchen, H.-U. (1994). Reliability and validity studies of the WHOComposite International Diagnostic Interview (CIDI): A critical review. Journal of Psychiatric Research, 28(1), 57-84.

Wittchen, H.-U., \& Jacobi, F. (2001). Die Versorgungssituation psychischer Störungen in Deutschland. BundesgesundheitsblattGesundheitsforschung-Gesundheitsschutz, 44(10), 993-1000. https://doi.org/10.1007/s001030100269.

Wittchen, H.-U., \& Jacobi, F. (2005). Size and burden of mental disorders in Europe-A critical review and appraisal of 27 studies. European Neuropsychopharmacology, 15(4), 357-376. https:// doi.org/10.1016/j.euroneuro.2005.04.012.

Wittchen, H.-U., Jacobi, F., Rehm, J., Gustavsson, A., Svensson, M., Jönsson, B., et al. (2011). The size and burden of mental disorders and other disorders of the brain in Europe 2010. European Neuropsychopharmacology, 21(9), 655-679. https://doi.org/10.1016/j. euroneuro.2011.07.018.

Wittchen, H.-U., Kessler, R. C., Beesdo, K., Krause, P., Höfler, M., \& Hoyer, J. (2002). Generalized anxiety and depression in primary care: Prevalence, recognition, and management. Journal of Clinical Psychiatry, 63(Suppl. 8), 24-34.

Wittchen, H.-U., Lachner, G., Wunderlich, U., \& Pfister, H. (1998). Test-retest reliability of the computerized DSM-IV version of the Munich-Composite International Diagnostic Interview (M-CIDI). Social Psychiatry and Psychiatric Epidemiology, 33(11), 568578. https://doi.org/10.1007/s001270050095.

Wittchen, H.-U., Mühlig, S., \& Beesdo, K. (2003). Mental disorders in primary care. Dialogues in Clinical Neuroscience, 5(2), 115-128 Retrieved from http://www.ncbi.nlm.nih.gov/pubmed/22034245.

Wittchen, H.-U., \& Pfister, H. (1997). Instruktionsmanual zur Durchführung von DIA-X-Interviews. Frankfurt: Swets \& Zeitlinger.

Wittchen, H.-U., Stein, M. B., \& Kessler, R. C. (1999). Social fears and social phobia in a community sample of adolescents and young adults: Prevalence, risk factors and co-morbidity. Psychological Medicine, 29(2), 309-323. https://doi.org/10.1017/S003329179 8008174.

Zimmerman, M., \& Chelminski, I. (2003). Clinician recognition of anxiety disorders in depressed outpatients. Journal of Psychiatric Research, 37(4), 325-333. https://doi.org/10.1016/S0022 -3956(03)00020-7.

Zlomke, K., \& Davis, T. E. (2008). One-session treatment of specific phobias: A detailed description and review of treatment efficacy. Behavior Therapy, 39(3), 207-223. https://doi.org/10.1016/J. BETH.2007.07.003.

Publisher's Note Springer Nature remains neutral with regard to jurisdictional claims in published maps and institutional affiliations. 